\title{
Research on the Fusion of Folk Beliefs in Fujian Area
}

\author{
Chen Jin Ping ${ }^{1, a}$
}

\author{
${ }^{1}$ Fuzhou University of International Studies and Trade, Fuzhou City, Fujian Province
}

\author{
Keywords: Fujian Area, Folk beliefs, Fusion
}

\begin{abstract}
Since ancient times, Fujian folk beliefs are particularly developed, the temple, hundreds of gods, frequent religious activities, many believers constitute the basic content of Fujian folk beliefs. Since the reform and opening up, due to the special historical conditions of Fujian and Taiwan, Southeast Asia, the close relationship between overseas Chinese, as well as the implementation of religious freedom policy, etc., Fujian folk beliefs have been faster recovery and development, causing great interest at home and abroad scholars. As an important part of Fujian and Taiwan regional culture, the formation of far-reaching traditional forces, Fujian and Taiwan society can't be underestimated the impact. Although the folk beliefs of Fujian and Taiwan have distinct regional characteristics, it is rooted in the fertile soil of the profound Chinese culture, which is derived from the long five thousand years of Chinese civilization. Fujian and Taiwan folk beliefs play an important role in the development of cross-strait relations and promote the improvement of political and economic exchanges between the two sides of the Taiwan Strait.
\end{abstract}

\section{Introduction of Folk Beliefs Fusion}

Fujian is located in the hilly area, the territory of mountain peaks, rivers and lanes, traffic inconvenience. For more than a thousand years, migrants into the Central Plains of the Central Plains of the Han people, most of the family moved south, into the Fujian and often gather together, the formation of different languages and customs. Due to the closure of the region and the differences between dialects, leading to Fujian people have a strong geographical concept. This kind of geography profoundly affects the regional characteristics of the folk beliefs. So far, Fujian's folk beliefs still have obvious regional characteristics.

Since the reform and opening up, with the implementation of agricultural household contract system, the rural family economic function is fully restored, decades of weakened clan forces to re-active. Due to the disintegration of the collective economy, the weakening of the ability of rural grassroots organizations to control, the blood of the clan became the preferred target of mutual social assistance. Fujian immigrants take folk beliefs to the southeast coast of radiation throughout Taiwan, Hong Kong and Macao, Southeast Asia and overseas. These kinds of nostalgic homeland, the root of the feelings are linked to the temple of Fujian temple, as the letter of faith back to Fujian's source ${ }^{[1]}$.

It should be pointed out that the ethical order of the traditional Chinese nationality is a patriarchal customs. It is based on the ancient agricultural economic base and the clan as the core of social organizations. The people's faith provides spiritual ties for the integration of grassroots organizations of traditional patriarchal society. And modern society, the new ethical order is a citizen equal right. It will be the rational basis of ethical order from transcendent to the city, from the patriarchal law to the right, from one dollar to multiple. Under the guidance of the spirit of the patriarchal ethical order will gradually weaken, which is the basic direction of social modernization. It is foreseeable that, with the historical process of modernization, the clan character of the contemporary people's belief will gradually fade.

\section{Characteristics of Folk Beliefs in Fujian}

The intellectual belief is an important part of the Chinese indigenous religious ecosystem, and it is also an example of the activation of the regional folk culture. Since ancient times, Fujian has a family tradition, a village is often composed of the family, so the creation of the village temple 
mostly funded by the family to build, the temple is also built for the family, the gods enshrined naturally become Family protection of God, folk beliefs in its development process deeply marked the clan of the clan. Fujian temples mostly worships are the ancestors of the ancestors of the wood family, reflecting the unique nature of the temple ${ }^{[2]}$. Fig. 1 shows the characteristics of folk beliefs.

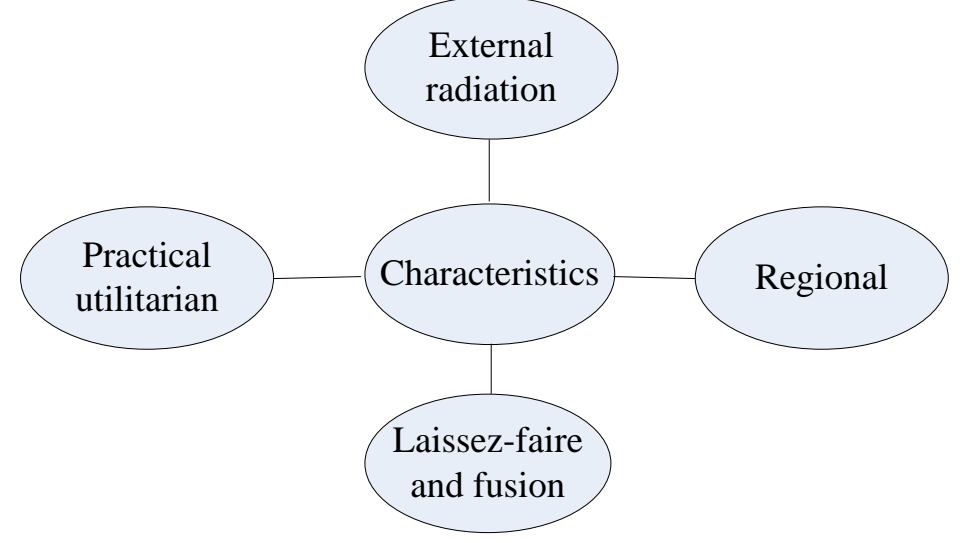

Fig. 1.The characteristics of folk beliefs

The practical utilitarian mentality of Fujian folk beliefs, for most of the good faith, is generally nothing to board the three treasures, have to ask the only burned kowtow to the temple, "usually not burning incense, temporary cramming" practical utilitarian mentality in Fujian Folk beliefs in the performance was very full. "Must have the spirit of" and "responsive" and "should be paid" to become a common attitude of Fujian folk beliefs. Because of the domination of practical utilitarian religious beliefs, in the eyes of the general believers, more than one more spiritual protection, the more gods can get more blessing, so a variety of gods are created a large number of almost flooded The point of disaster. In a word, as long as the need, you can put any character, things shaped as idol worship. In connection with the laissez-faire of faith, Fujian's folk beliefs are characterized by fusion. The same person, he can be a Buddhist believer, it can be a Taoist believers, but also can believe in Christianity or other religions.

The natural environment of the coastal areas of Fujian leads to economic life of fisheries and sailing, so the gods of the gods prevailed. Fujian plain area fertile, rich in rice, folk beliefs activities all are around the rice production. Fujian mountain area generally believes in the mountain god. Fujian folk beliefs are also influenced by dialects. Mazu can break the dialect boundaries of the gods is not too much, the more common case is that different dialects between the folk beliefs more or less there are differences. Fujian folk beliefs are also affected by the nation. Fujian folk belief in foreign radiation and overseas trade and overseas immigrants linked to the main three external routes: one is to spread to Southeast Asia; the second is to spread to the local. The third is to spread to the Ryukyu. Especially since the 21st century, with the Fujian people moved to Europe and the United States, Fujian folk beliefs also spread to Europe and the United States ${ }^{[3]}$.

\section{Folk Beliefs and Folk Custom Fusion}

Folk beliefs will continue to integrate with the folk, folk beliefs of the main participants is the elderly to penetrate into all aspects of people's lives, with China into the elderly society, the temple became a place often gathered in old age, and even become the local elderly association office space, This trend will continue to develop, the functions of the folk temple of the entertainment will be further strengthened. Multi-ethnic Chinese civilization has a strong inclusive, the original religious nature of the people can also be in the context of civilization, and heterogeneous religious culture blend, so as to adapt to the needs of the people ${ }^{[4]}$.

In the strict sense, the folk beliefs have not yet been included in the protection of religious law, therefore, with the continuous development of China's legal system, folk beliefs for legal status will continue to rise. In the near future, folk beliefs will continue to take roundabout tactics, attached to the Taoist Association or the Buddhist Association, for the protection of the law. One of the main reasons why folk beliefs choose Taoist associations and Buddhist associations as umbrellas is that 
folk beliefs are inextricably linked to Taoism, Buddhism, religion, religion, religion, religion, religion, religion, religion, religion, religion, religion Recognition and absorption. The religion produced by the people is more tampered with and used by the rulers, and religions such as Buddhism, which are both foreign and non-popular, do not cater to the tastes of the rulers, and are sometimes marginalized, but the world of Buddhism The promise is deeply attracted by the Chinese believers. In addition, although the various religions are independent of the system, they exist in human society, and there is a certain relationship between them. Fujian folk beliefs most distinctive local cultural representatives, but also one of the famous beliefs in the history of Chinese religion, Buddhism as a foreign religion, broad and profound culture from the unspeakable, to explore the relationship between the two, help us to understand the religion Social and humane.

Because all religions are always based on believers, this is their common medium, on the contrary, through the exploration of the relationship between various religions, but also from the spiritual level to deepen the understanding of mankind. Spirit is more difficult to understand and identify than helpless, the exploration of the nature of human nature may sometimes enter the lost, from the side, the religion is the mirror of the human soul, a variety of religions to promote each other actually reflects the growth of human consciousness, It is necessary to study the interrelationships of religions. Religion reflects the human consciousness, religion is the media of human feelings, as the Mazu faith, not only to connect the world of Chinese, but also the spirit of cross-strait compatriots, Fujian folk Mazu faith witnessed the same compatriots on both sides of the same root, Change, can't be changed. The inclusiveness of Chinese civilization has long been the diversity of Chinese culture, which can be closely linked to the Chinese around the world, because the common sense is not isolated, can only be more closely linked to each other and promote the common religious beliefs a steady stream.

\section{New Development of Fujian Folk Belief Communication}

Before the reform and opening up, the people of Taiwan have been unable to achieve the desire of the ancestral temple of Fujian ancestors, they will be homesickness into the Taichung Kai Temple into the activities of the incense. Such as the big Mazu south of Hong Kong into Hong, every year to meandering in the number of trumpet, tens of thousands of people trek more than two hundred kilometers, through the central coastal counties and cities fifteen township five or sixty temples ${ }^{[5]}$. Fig.2 shows Fujian folk beliefs ancient architecture.

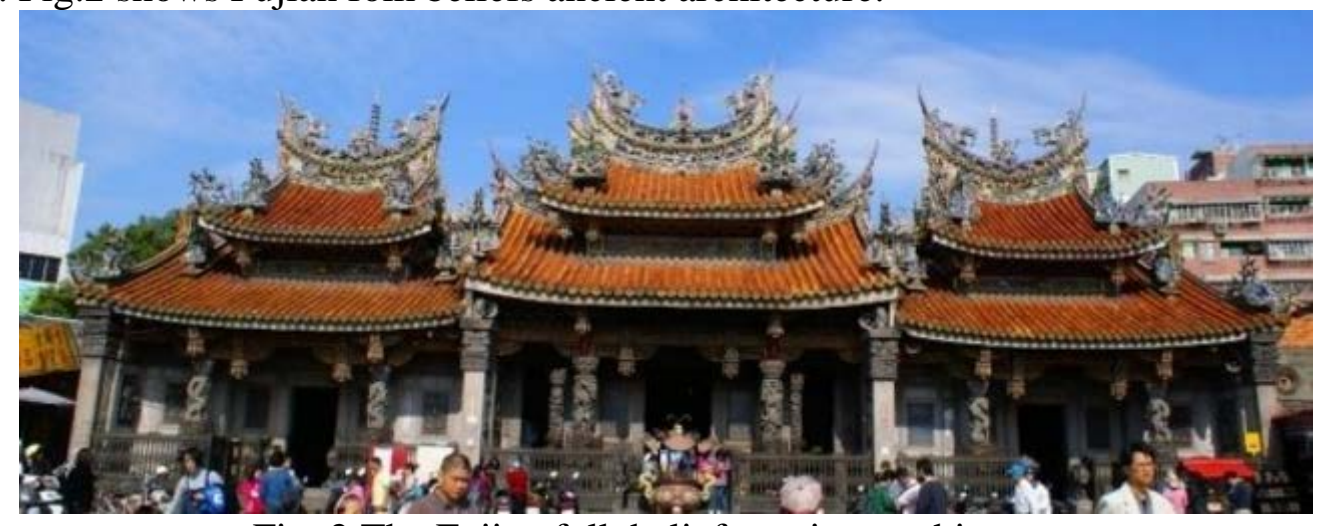

Fig. 2.The Fujian folk beliefs ancient architecture

On the one hand, Hakka folk beliefs contain the contents of traditional culture. Hakka ancestors from the Central Plains region, Hakka culture retains a large number of Central Plains traditional cultures. On the other hand, folk beliefs also contain a number of positive, well-behaved content. To persuade people to be good is the basic content of religious ethics, almost all religions are very demanding to do more good faith, in order to have a good result. Hakka folk beliefs also contain a lot of positive and persuasive content. Taiwanese folk believers have been holding the worship of the gods to Fujian ancestral temple into the thirsty ancestors, as Fujian and Taiwan cultural exchange of a beautiful landscape, objectively and effectively promote the development of cross-strait relations. 
Taiwanese believers to Fujian ancestral temple incense is an endless stream, doubled to increase, come to Mazu ancestral temple of Taiwan compatriots every year there are hundreds of thousands, the rapid development of a national tourist resort, to promote development of the local economy. Particularly noteworthy is that this period of Fujian and Taiwan folk beliefs of the exchange of new forms, that is, the main god of Fujian invited to go to Taiwan parade, accept the worship of believers. With the further active economic, political and cultural exchanges between the two sides of the Taiwan Strait, the strong feelings of Taiwan Mazu believers "worship Matsu. Half a century of spring and Taiwan long-awaited direct desire to become a reality, the two places from the sea traffic history opened a new page.

\section{Conclusions}

Since the reform and opening up, Fujian folk belief in the exchange of new development, in addition to thousands of Taiwanese believers come to Fujian ancestral temple into the thirsty ancestors, the ancestors of Fujian ancestral temple also invited frequent cruise to Taiwan, accept believers worship vigorously carry out the development of folk beliefs tourism, promote the economic development of Fujian. As a primitive religious form of culture, folk beliefs have their own characteristics and requirements of the activities. In the process of tourism development of folk beliefs, we must respect the local customs and customs, and strictly abide by the various taboos in folk beliefs. This is not only respect for the Hakka folk beliefs, but also an important guarantee for the sustainable development of folk beliefs. A comprehensive understanding of the status quo of Fujian folk beliefs, a correct understanding of its characteristics, scientifically predict its development trend is undoubtedly of great significance.

\section{Acknowledgements}

In this paper, research projects are social science research, 2016 years young project in Fujian province department of education'"Traditional social folk belief between Fujian and Taiwan therapy analysis $\backslash "$ (JAS160727).

\section{References}

[1] Gan County Committee of the CPPCC historical data Hakka village from Heron Circle .2002...

[2] Qiu Xinmin Hakka Millennium Village - Tung Lung [J], Tian Bu Xiang People's Government, Nanjing County History Office, 2007: 38-39.

[3] Liu Shanqun. Ning hua ancestral hall big dagger [J]. Beijing: China Culture Press, 2012: 3.

[4] Cai Wu, adhere to the construction of cultural advance "The Belt and Road" [J], seeking, 2014. (9) 4446.

[5] Zhengheng Mi, Adjustment and Reconstruction: Taoism and Standardization of Folk Beliefs in the Process of Urbanization. World Religious Culture, 2014 (6):76-79. 